\title{
REVISTA
}

D E

ESTUDIOS DE LA VIDA LOCAL

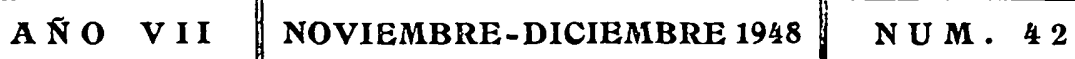

\section{El Contencioso-administrativo}

\section{de las Corporaciones locales y el Real Decreto-} Ley de 14 de septiembre de 1925

I.-Corriendo los tiempos del Gobierno del General Primo de Rivera, se promulgó un Real Decreto-Ley, fechado en $\mathbf{1 4}$ de septiembre de 1925 y publicado en la "Gaceta" de dos días después, cuyos preceptos ocasionaron en aquel entonces gran revuelo, dada la trascendencia de los mismos en orden al régimen jurídico de las Corporaciones locales, y que aún hoy, a más de veinte años de distancia, presentan un interés de primera fila, acrecentado por las particulares circunstancias que concurren respecto a la vigencia de tal disposición.

El indicado Decreto-Ley prescribía:

Artículo $10^{\circ}$ Las personas individuales y jurídicas interesadas directa o indirectamente en los àcuerdos de Autoridades o Corporaciones municipales o provinciales, podrán impugnarlos mediante recurso contencioso-administrativo, considerándose a tal efecto comprendidas en el número $2 .^{\circ}$ del art. $253 \mathrm{del}$ Estatuto municipal.

Art. 2. En los recursos contencioso-administrativos que se interpongan contra acuerdos de las autoridades y organismos municipales y provinciales, al amparo de los Estatutos municipal y provincial y de sus Reglamentos, sólo podrá proponerse por los Fiscales y declararse por los Tribunales la excepción de incompetencia de jurisdicción cuando se trate: $10^{\circ}$, de las cuestiones de índole civil o criminal pertenecientes a la ju- 
risdicción ordinaria, $y$ de aquellas que por su naturaleza sean de la competencia de otras jurisdicciones especiales; $2 .^{\circ}$, de las resoluciones que no hayan causado estado; $3 .^{\circ}$, de resoluciones que sean reproducción de otras anteriores que hayan causado estado y no hayan sido reclamadas o confirmatorias de acuerdos consentidos por no haber sido apelados en tiempo y forma; y $4 .^{\circ}$, de resoluciones que se hayan dictado con arreglo a una ley que expresamente la's excluya de la vía contenciosa.

Art. 3. ${ }^{\circ}$ Cuando un Tribunal contencioso-administrativo se declare incompetente para entender en un recurso promovido contra acuerdos municipales y provinciales, en la resolución que en tal sentido se dicte deberá expresarse cuál es la jurisdicción competente, sin cuyo requisito será nula la excepción admitida.

Art. $4 .^{\circ}$ No podrá proponerse por el fiscal ni admitirse por los Tribunales contencioso-administrativos la excepción de incompetencia cuando por inexistencia de jurisdicción gubernativa en materia municipal y provincial, dicha declaración produjese indefensión en los interesados o vecinos que hubiesen instado la revisión de un acuerdo al amparo de preceptos legales vigentes.

Art. 5. ${ }^{\circ}$ Quedan derogadas todas las leyes y disposiciones que se opongan a lo dispuesto en el presente Real Decreto.

La diversidad de los preceptos contenidos en estos artícúlos, $\dot{y}$ las aludidas particularidades que ofrece el problema de su derogación o subsistencia actual, determinan la necesidad de proceder a un estudio separado de cada uno de ellos, habiéndonos de limitar por nuestra parte a los que estimamos de mayor interés y en los que creemos poder hallar soluciones de inmediata efectividad práctica, dentro de las directrices generales de nuestro ordenamiento jurídico (1):

(1) En relación con el art. 3..$^{\circ}$ que dejamos al margen de nuestro estudio, se ha de decir que por el excesivo rigor de la norma en él sancionada, de la que podia deducirse que la voluntad o negligencia de los recurrentes determinara la imposibilidad de la estimación de la excepción de incompetencia de jurisdicción, no fué aplicado por los tribunales. (V. sentencia del T. S. de 24 de febrero de 1230). 
En primer lugar, y por su artículo $1 .^{\circ}$, ratificaba el referido Decreto-Ley de 14 de septiembre de 1925 la posibilidad, respecto a los acuerdos municipales, de recurrir contra ellos tanto por lesión de derecho como por infracción de disposiciones administrativas con fuerza legal, por personas directa o indirectamente interesadas.

Las razones motivadoras de esta especial declaración, en sus más amplios términos ya contenida en el artículo 253 del Estatuto municipal, nos las indica claramente la exposición de motivos de aquel Decreto-Ley. "Una de las reformas fundamentales introducidas por el Gobierno en el régimen local español -decía-, consiste en haber suprimido los recursos gubernativos sustituyéndolos por los judiciales. Tal reforma exigía, naturalmente, medidas encaminadas a facilitar el procedimiento contencioso... Pero la práctica nos demuestra que no siempre se ha interpuesto (2) rectamente el espíritu del legislador, y así, unas veces al amparo de textos legales ambiguos, otras en franca pugna con la letra y la orientación de los mismos, algunos tribunales sentaron doctrina de perniciosa trascendencia, cuya repercusión interesa evitarn.

Esto es, claramente expresa que la norma del art. $1 .^{\circ}$ tendía a que por los tribunales se diese cumplimiento de los terminantes preceptos del art. 253 del Estatuto municipal, y a acabar con un estado de cosas en la actuación de los mismos contrario al imperio de la legalidad establecida.

Pero es que además, lo transcrito de la dicha exposición de motivos nos da la pauta para resolver una cuestión, de indudable actualidad y hasta hoy no bien percibida, respecto a la revisibilidad de los acuerdos de las Corporaciones provinciales. En efecto, la referencia que el art. $10^{\circ}$ del Decreto-Ley realiza para cuanto en él se dispone, tanto al orden provincial como municipal, y la alusión que formula la exposición de motivos a textos legales ambiguos, indica que se trataba de resolver la antinomia resultante de los arts. 169 y 170 del Estatuto

(2) Asi aparece en la Gáceta», debiendo, naturalmente, haber querido decir interpretado. 
provincial; de la cual, por lo visto, y pese al breve lapso transcurrido entre la promulgación del Estatuto -20 de marzo de 1925- y la de este Decreto-Ley - 14 de septiembre del mismo año-, la jurisprudencia, sin duda por la inmediatividad de la vigencia del libro I de aquél, en el que se contiene esta materia, se había hecho ya eco.

Veảmos. El art. 169 del Estatuto provincial reza así: "Los restantes acuerdos de las Diputaciones provinciales en pleno, $\mathrm{y}$, en su caso, los de las Comisiones provinciales (viene del artículo anterior), con excepción de los de carácter económico administrativo comprendidos en el libro II de esta Ley, causarán estado en la vía gubernativa y contra ellos sólo se darás el recurso contencioso-administraitivo o el judicial de indole civil o criminal, cuando los intcresados consideren vulnerados sus derechos o infringidals disposiciones legales". Así expresado, esto es, continuada la oración tras la palabra "administrativo" y no interrumpida hasta la voz "criminal", es indudable que a todo lo anterior se aplica la referencia a infracción de disposiciones legales, y que, por tanto, pugna este artículo con el 170, que limita el recurso contencioso-administrativo a los supuestos de lesión de derechos reconocidos, según claramente resulta de sus dos párrafos.

Por este art. $1 .^{\circ}$ del aludido Decreto-Ley de 14 de septiembre de 1925, para salvar dicha antinomia, se sancionaba la aplicación en el orden provincial del contencioso objetivo -y obsérvese que el art. 169 del Estatuto habla de cinteresados»-, y aparte y además la acción popular, en aquel Decreto-Ley también incluída, dada la cláusula derogatoria de su art. $5 .^{\circ}$ y el carácter de! precepto. (Véase sentencia de 17 de enero de 1930).

En segundo lugar, el Decreto-Ley establecía normas por las que se limitaba el juego de la excepción de incompetencia de jurisdicción a los casos que taxativamente se señalaban.

La propia exposición de motivos nos dice a este respecto: "Ya de paso, el Gobierno desea poner trabas a la excepción de incompetencia de jurisdicción, que esgrimida con excesiva facilidad constituye desde luego arma peligrosa... y precisamen- 
te porque el nuevo régimen local fortalece la personalidad de los Ayuntamientos y Diputaciones, ensanchando considerablemente la órbita de sus facultades, se necesita más que nunca asegurar a los ciudadanos la revisión de los acuerdos municipales y provinciales que hayan podido lesionar con injusticia sus intereses o derechos. De ahí el condicionamiento de la expresada excepción que sólo será alegable en los casos que se indican".

Es claro que ya en aquel entonces el Poder público había captado los riesgos que para la justa actuación de la jurisdicción contencioso-administrativa implica la excepción de incompeten. cia de jurisdicción - hoy aumentados al ser mayor el número de caso's en que, quedando sin apelación las sentencias de los Tribunales provinciales, falta el control de resoluciones muchas veces más apegadas a la doctrina tradicional del propio Tribunai que a la jurisprudencia del Supremo- y para evitarlos realizaba la declaración limitativa que queda reseñada al transcribir el artículo $2 .^{\circ}$ de este Decreto-Ley.

En aplicación del mismo, la jurisprudencia declaró la inadmisibilidad de la excepción de incompetencia de jurisdicción fundada, ya en la ausencia de derecho administrativo lesionado, tanto en el orden provincial como municipal (sentencia de 3 de enero y auto de 26 de mayo de 1930); ya en el carácter general de la disposición reclamada, habiendo sido alegada la excepción como dilatoria (sentencia 18 de febrero de 1931); ya por versar el acuerdo sobre materias de la llamada potestad discrecional (sentencias de 4 de marzo de 1930 y 14 de febrero de 1931).

En orden a este último supuesto, es de hacer notar la acogida poco favorable que en algunos medios oficiales tuviera el precepto en cuestión. Acerbamente fué criticado por la propia Fiscalía del Tribunal Supremo, en su Memoria de 15 de septiembre de 1926, en la que se llegaba a decir, con indudable menosprecio para la educación cívica nacional que queriendo dar un escudo defensivo a los ciudadanos se había creado una red peligrosa para que se estorbase e hiciera ineficaz la acción fecunda de las Diputaciones y Ayuntamientos, al suprimir las 
trabas del desahogo de la pasión poniendo en manos de aquéllos, con tal amplitud, un recurso gratuito y que no exige representación ni dirección técnica. Llegando a sostener dicha Memoria, con notorio olvido de una de las más acabadas y mejor logradas conquistas del Derecho Administrativo contemporáneo, que o se suprimía lo contencioso-administrativo o no era dable que fueran revisadas las resoluciones dictadas por la Administración en ejercicio de facultades discrecionales.

También se dijo que hubiese sido preferible prohibir simplemente que las excepciones fuesen estimadas con el carácter de dilatorias, pues ello hubiera bastado para evitar todos los males que se trataba de prevenir, por lograr interesar a los Tribunales para que al resolver de aquéllas como perentorias entrasen en el fondo del asunto $\mathrm{y}$ en las razones jurídicas por cada parte aducidas (3).

Equivocada suposición. La ulterior experiencia confirma que no obstante la reiteradísima y constante jurisprudencia del Tribunal Supremo en orden a la excepción de incompetencia de jurisdicción, principalmente en los casos de falta de lesión de derecho administrativo, determinando la necesidad de abordar la materia de la litis, con gran frecuencia los Tribunales provinciales sostienen otro criterio, quebrando la unidad de principio al amparo de la falta de apelación -extendida hoy no sólo por la cuantía, sino también por la materia cuando se trata de cuestiones de personal, según el art. $7 .^{\circ}$ de la Ley de 18 de marzo de 1944-, absteniéndose la mayoría de las veces de consideraciones de fondo del litigio y limitándose tan sólo, en términos abstractos, a la justificación de la inéxistencia del derecho que se alega, no raras veces con construcciones de lo más artificiosas.

Por ello, hemos creído de especial interés realizar este estudio, limitado en este segundo extremo al caso de incompetencia de jurisdicción por falta de lesión de derecho administrativo. Dado también que, como al principio queda expresado, las particularidades que ofrece el problema de la vigencià

(3) MARTfin Retortillo: Algo sobre lo contercioso administrativo munsipal. Zaragoza, 1926, pág. 22. 
actual del Decreto-Ley de 14 de septiembre de 1925, determinan en cada uno de los supuestos por él contemplados la necesidad de una consideración especial, que ofrece las mayores posibilidades, a nuestro parecer, en los puntos a que nos concretamos.

II.-Abordemos, pues, la cuestión. En primer término, digamos que no hemos encontrado en los conceptos correspondientes a Jurisdicción contencioso-administrativa, Ayuntamientos, Gobiernos civiles, Diputaciones provinciales, ni tampoco en el relativo a Ministerio Fiscal, en relạción con las Circulares Instrucciones que por la Fiscalía del Tribunal Supremo se dictan para los Fiscales de lo contencioso en los Tribunales provinciales, ningún precepto que haga derogación expresa del aludido Decreto-Ley de 14 de septiembre de 1925, y ello desde su promulgación hasta la fecha.

En segundo lugar, tampoco resulta tal derogación de los decretos ministeriales promulgados a raíz de la proclamación de la segunda República española, dictados a tenor del de revisión de 15 de abril de 1931, sobre cuya consideración especial luego volveremos. Así, nada se dice respecto a la indicada derogación en los Decretos de la Presidencia del Gobierno de 14 y 18 de mayo, ni en el del Ministerio de Justicia de 31 del mismo mes y año de 1931, ni en los del Ministerio de la Gobernación de 16 y 20 de junio.

La Circular de la Fiscalía del Tribunal Supremo de 19 de julio de 1933, que dió instrucciones respecto a disposiciones derogadas y vigentes, y aclaró el sentido de determinadas normas de procedimiento en el contencioso-administrativo, tampoco alude al Decreto-Ley de 14 de septiembre de 1925, como lo propio sucede con ulteriores circulares, incluso la de 12 de enero de 1940.

Afecta, sin embargo, a dicho Decreto-Ley, la vigente Ley municipal de 31 de octubre de 1935 , pero únicamente en lo que toca a la llamada acción popular, por la misma suprimida.

La Ley de 18 de marzo de 1944, restauradora en la esfera de la Administración central de la jurisdicción contencioso-administrativa, para nada roza el contencioso de las Corporacio- 
nes locales, como no sea en lo previsto en su art. $7^{\circ}$ en orden a la materia de personal y la inapelabilidad en dichos casus de las sentencias de los Tribunales provinciales, por lo que tampoco se la puede considerar derogatoria del precepto cuya consideración realizamos en estas páginas. De otra parte, de los términos del art. $1 .^{\circ}$ de dicha Ley de 18 de marzo de 1944 no estimamos puede extraerse consecuencia alguna a nuestro fin, puesto que de ellos no resulta sino que en la esfera de la Administración central, y sólo en ella, se restablecía en iodos su's.alcances la Ley reformada de 22 de junio de 1894 con las solas modificaciones ein aquélla determinadas. Entender ơtra coisa equivaldría, por ejemplo, a dar por modificada a este respecto la Ley municipal de $\mathbf{1 9 3 5}$, ssupuesto no admitido.

Por último, la nueva Ley de Bases de 17 de julio de 1945, naturalmente que nada podía decir que nos sirviera de pauta al extremo que estamos contemplando, pero sí contiene un pronunciamiento digno de tenerse en cuenta pese a su no articulación hasta la fecha, y, por tanto, su no vigencia en esta materia; y es el criterio de la Base 59 de establecer indistintamente para las esferas municipal y provincial tanto el contencioso de plena jurisdicción como el de anulación.

Mas volvamos ahora, para su especial análisis, al Decreto de 15 de abril de 1931. Por él se prescribió que desde la fecha de su promulgación a la del 31 de mayo de tal año, los diversos Ministerios revisaran la obra legisladora de la Dictadura, proponiendo con respecto a las disposiciones legales de la misma, ya la derogación con efectos retroactivos, ya la derogación con respecto de las situaciones jurídicas creadas a su amparo, ya la reducción al rango reglamentario de cualquier disposición, ya su subsistencia en todo o en parte por exigencias de la realidad o excepcional conveniencia del interés público. Dicho queda, que por los diversos decretos que se dictaron como consecuencia de éste, dentro y aun fuera del plazo señalado, ninguna mención específica se contiene en relación con e! que consideramos, en ninguna de las dichas categorías.

Sin embargo, el art. 2. ${ }^{\circ}$ del Decreto de 15 de abril de 1931 dijo: "Si dentro del plazo que fija este Decreto hubiera ne- 
cesidad urgente, no aplazable, de aplicar por los Tribunales - la Administración algún Decreto-Ley aún no ratificado, se entenderá comprendido en el grupo $c$ ) de la enumeración precedente. Igual carácter se entenderá atribuído a los titulados Decretos-Leyes de la Dictadura que al llegar el $10^{\circ}$ de junio no hubieran sido objeto de otra distinta y expresa declaraciónn: lo que ha de ponerse en relación con dicho apartado c) que decía: "Reducidos al rango de preceptos meramente reglamentarios, sólo válidos y aplicables en cuanto se conformen con el texto anterior y superior de leyes votadas en Cortesn.

De ello, la primera y evidente consecuencia que hay que deducir es que el Decreto-Ley de 14 de septiembre de 1925 no fué derogado, interesando considerar a renglón seguido el alcance de esta consecuencia, a cuyo objeto conviene analizar por separado los dos supuestos que hemos contemplado de las disposiciones de dicho Decreto-Ley, al fin de precisar si pueden o no ser aplicados según lo dispủesto por el Decreto de 15 de abril de 1931.

Respecto al primero de los dichos supuestos, la Jurisprudencia se ha pronunciado. Así, la sentencia de 5 de diciembre de 1933 desestimó un recurso de los de carácter de acción popular en la esfera provincial en razón de que el art. 170 del Estatuto en la materia de recursos no da entrada al de acción popular.

Doctrina correcta, más aún puesta en relación como está con las consideraciones de la exposición de motivos del propio Estatuto provincial, en la que al hablar de los recursos que se establecen se dice que serán los mismos del Estatuto municipal, con "la única salvedad de la acción pública».

La propia sentencia dice además, comentando el párrafo $1 .^{\circ}$ del art. 170 del Estatuto provincial, que su alcance no es otro que el de no autorizar el recurso "por lesión de mero interés, o sea, el de acción popular", lo cual ya a nuestro juicio es una afirmación errónea. Pues si bien el art. 253 del Estatuto municipal al iniciar nuevos derroteros en nuestra legislación no establecía otra cosa que la amplitud de la acción popular, el Real Decreto que comentamos, en su art. 1. ${ }^{\circ}$, al hablar de 
reclamaciones de personas directa o indirectamente interesadas en los acuerdos de las Corporaciones provinciales y municipales, creemos que sentó ya en sus debidos términos la diferencia que existe entre el contencioso de legalidad por interés agraviado - como diría luego la Ley municipal de 1935- directamente sentido por el recurrente -como mejor precisaria la Ley de Bases de 1945-, y la mera acción popular, que no requiere tal agravio directo al interés personal.

Sin desarrollar criterio alguno la sentencia de 31 de mayo de 1935 no admitió el recurso contencioso objetivo en el orden provincial.

$Y$ finalmente, nos encontramos con la sentencia de $\mathbf{1 7}$ de enero de 1942, en la que, al desestimar un caso que consideraba de ejercicio de la acción popular contra un acuerdo provincial, se dice: "Considerando que la acción contenciosa es de índole personal y privada y se dirige a restablecer un derecho subjetivo vulnerado, $y$, en consecuencia, solamente quien se estime objeto de agravio por las resoluciones particulares de la Administración puede ejercitarla... contra los acuerdos de las Diputaciones provinciales que regulan el art. 170 del Estatuto de 20 de marzo de 1925, cuyos términos literales no dejan lugar a duda, y menos aún la más auténtica y autorizada interpretación de su sentido y alcance prohibitivo contenida en la exposición de motivos de aquel cuerpo legal; sin que puedan oponerse a estas prescripciones las del Real Decreto de 14 de septiembre de 1925, reducido al rango de precepto reglamentario conforme al apartado c) del Decreto revisor de 15 de abril de 1931, al no haber sido objeto de distinta y expresa declaraciónn.

Ante $\tan$ expresivo pronunciamiento, vamos a intentar centrar la cuestión en sus verdaderos términos, según nuestro punto de vista.

Por la aludida revisión de 1931, y en la forma global que se indica, el Decreto-Ley de 14 de septiembre de 1925 quedó vigente con carácter reglamentario, y válido y aplicable en cuanto sea conforme con el texto anterior de Leyes vigentes. No hay que decir, aun cuando tampoco derivaria dificultad 
aiguna de ello, que esa referencia al "texto" de leyes anteriores, no pudo estar puesta en relación con el texto literal, sino con el contenido de dichas leyes.

Al fin reglamentario indicado, se ha de reconocer, por tanto, a los preceptos que de esta forma se dejaron subsistentes, la idoneidad de la propia función reglamentaria, esto es, de desenvolvimiento y aclaración de las normas legales.

$\mathrm{Ha}$ de considerarse además, que el Estatuto provincial se dejó subsistente en la materia relativa al caso que nos ocupa, por el Decreto de 16 de junio de 1931, y que por tanto, dado su carácter, es de aplastante lógica equipararlo a estos fines - puesto que además, y ello es obvio, era precepto anterior al Real Decreto de 14 de septiembre de 1925 - a las leyes votadas en Cortes; exigibilidad esta última que claramente se percibe era más doctrinaria que jurídica.

$Y$ es al fin de apreciar la conformidad o disconformidad del artículo $1 .^{\circ}$ de dicho Real Decreto con el articulado del Estatuto provincial, para de ellas derivar la posibilidad o impos:bilidad de la actual aplicación de aquél, con el carácter reglamentario dicho, como complementario de éste, al que conviene la distinción que anteriormente dejamos señalada se consignaba en dicho artículo, de personas directa o indirectamente interesadas en los acuerdos de las Corporaciones municipales y provinciales.

Porque las indirectamente interesadas se comprenden con toda evidencia en el caso de la acción popular, pero las del primer supuesto están sin duda incursas en el contencioso, objetivo o de legalidad; estableciéndose ya, por tanto, en dicho Real Decreto de 14 de septiembre de 1925 , y en su art. $1 .^{\circ}$, esta diferenciación no señalada en el 253 del. Estatuto municipal.

Por ello es evidente, que cuando dicho Real Decreto declaraba que los indirectamente interesados en los acuerdos de carácter provincial adoptados con infracción de disposiciones legales podian reclamar contra ellos, es claro que introducía en el régimen de los mismos el ejercicio de la acción popular; elemento nuevo por no admitido en el Estaluto provincial, según se desprende de la exposición de motivos de éstè como 
auténtica y aưorizada interpretación a que invoca la referida sentencia de 17 de enero de 1942.

Pero en cambio, el propio precepto no hace otra cosa que discernir los exactos límites del dicho Estatuto provincial, cuando faculta para recurrir a los directamente interesados en los acuerdos por infracción legal, puesto que no viene sino a aclarar el sentido de los antinómicos arts. 169 y 170 del Estatuto dicho. Tiene, por tanto, carácter aclaratorio de la dificultad nacida de que dos artículos consecutivos se eśtén contradiciendo, al admitir uno la reclamación "cuando los interesados conside:en vu'nerados sus derechos o infringidas disposiciones legales", y el otro sólo por lesiones de derechos: Tal carácter lo ponía ya de manifiesto la exposición de motivos del Decreto-Ley, cuando, como antes vimos, nos habla de "textos ambiguos"; así como el propio preámbulo del Estatuto provincial, que alude excluyentemente a la acción pública, pero no al supuesto del contencioso objetivo, cuyo alcance no se hallaba suficientemente matizado, aunque estuviera apuntado en el art. 169.

Refuerzan nuestra argumentación las propias palabras de la aludida exposición de motivos del Estatuto provincial, que al explicar la exclusión de la acción popular en la esfera provincial alegaban que ella "no se halla en contacto directo ni con todos ni siquiera con la mayoría de los ciudadanos"; en las que se prueba que lo que se quería excluir era sólo la acción pública y no los casos en que ese contacto directo puede darse. $Y$ siendo así que esa inmediatividad de posible interés derivado del contacto directo es lo que distingue el contencioso de legalidad de la acción pública, es evidente que se quiso excluir ésta pero no aquél; y que si en ello no se hizo luz fué por la indistinción legalmente existente entre ambos, con la que, como hemos visto, vino a acabar el Decreto-Ley de 14 de septiembre de 1925, que además de lo dicho, y a mayor abundamiento, diferenciaba con claridad, como puede verse en su artículo $4 . .^{\circ}$, el concepto uinteresado" del concepto "vecino".

Por tanto, insistimos, cuando el art. $1 .^{\circ}$ del Decreto-Ley, a través de la locución "personas directamente interesadas", lleva 
el contencioso objetivo a la vida provincial, no modifica el Estatuto, simplemente aclara el sentido de sus preceptos, confusos y contradictorios, como hemos visto en este punto.

Según todo ello, debemos deducir que el Decreto-Ley de 1925 es, en tal materia, conforme al texto del Estatuto provincial, por cuanto no realiza sobre el mismo otra misión que la de aclarar sus normas, y con tal carácter aclaratorio y complementario estimamos debe ser hoy considerado vigente, a isecuencia del alegado Decreto de 15 de abril de 1931, de aplicabilidad reconocida por la sentencia de 17 de enero de 1942 , puesto que se cumple en este caso el requisito exigido para la aplicación de los preceptos reducidos por dicho Decreto al rango reglamentario.

Con lo expuesto no pretendemos arrogarnos atribuciones en orden a sentar doctrina que ni por competencia ni por función nos corresponden. Sólo intentamos demostrar cómo, a nuestro juicio, no hay motivo para, aferrándose a la literalidad de las palabras, dejar subsistir una situación irregular con respecto a la revisibilidad de los acuerdos de las Corporaciones provinciales, al ser objeto de un trato distinto al de los municipales, siendo así que no se aprecian motivos ideológicos para ello, que existen preceptos legales que rectamente interpretados pueden estimarse en vigor con tal fin, y que el criterio. de los órganos legislativos del Estado, expresado en la Base 59 de la Ley de 17 de julio de 1945, es idéntico al que patrocinamos mediante esta argumentación en pro de la vigencia a dicho respecto del Real Decreto-Ley de 14 de septiembre de 1925.

III.-Menores son las consideraciones que precisa el segundo extremo que abordamos de los regulados por el reiteradamente citado Decreto-Ley.

Establecido ya el alcance que a éste hay que reconocerle hoy día, para determinár su vigencia respecto a la inadmisibilidad de la excepción de incompetencia de jurisdicción por falta de lesión de derecho administrativo en el contencioso de las Corporaciones locales, basta con considerar que en este punto puede estimarse complementario de la Ley orgánica de la juris- 
dicción contencioso administrativa, a través de la mención del fárrafo $2 .^{\circ}$ del art. 256 del Estatuto municipal -hoy reproducida en el 225 de la Ley vigente de 31 de octubre de 1935-, en relación con el 170 , también párrafo $2 .^{\circ}$, del provincial; subsistentes ambos según el Decreto de 16 de junio de 1931, y al margen la primera de la acción revisora de la República.

Porque en efecto, al excluir que la incompetencia de jurisdicción basada en falta de lesión de derecho administrativo pueda ser apreciada como excepción, no se altera la esencia de la antedicha Ley orgánica por no afectar ello en nada a la sustancialidad del recurso, siendo simplemente el establecimiento de una norma de conducta que, conformándose al texto de la Ley, tiende a dar garantía de que en las actuaciones judiciales a tenor de ella se realizará, con la debida contemplación de los extremos del litigio, el análisis de la procedencia de la reclamación entablada; considerando debidamente la aplicabilidad de los fundamentos legales aducidos por las partes.

No implica, pues, que la improcedencia del recurso pueda ser declarada por falta de lesión de derecho, sino que este supuesto sea sancionado por vía de excepción.

Con ello se trata de evitar lo que, como antes decimos, ocurre con tanta profusión, y es que pese a que la excepción no sea estimada como dilatoria, y siga por tanto el curso del procedimiento, sustanciado éste y llegado el momento de pronunciar sentencia los tribunales adopten la posición hoy tan difundida de estimarla como perentoria (pese a la jurisprudencia contraria del Supremo), no entrando en el fondo de la litis, siendo así que el número $3 .^{\circ}$ del art. $10^{\circ}$ de la Ley de 22 de junio de 1894 afecta al fondo y no a la admisibilidad del recurso, para la cual basta con su alegación.

Por consecuencia, reiterándonos en lo expuesto sobre la vigencia del Real Decreto-Ley de 14 de septiembre de 1925, para cuya consideración partimos de las declaraciones del Tribunal Supremo en la mencionada sentencia de 17 de enero de 1942, hemos de estimar también que la prohibición de dicho Decreto-Ley sobre la formulación por los Fiscales y admisibilidad por los tribunales provinciales de lo contencioso administrati- 
vo, de la excepción de incompetencia de jurisdicción por ausencia de lesión de derecho administrativo -en cuanto tal motivo de excepción no se comprende en los reseñados en el art. $2 .^{\circ} \mathrm{de}$ dicho Decreto-Ley- debe seguir siendo tenida en cuenta como vigente, por estarlo a este respecto, con el concepto reglamentario dicho, el aludido Decreto-Ley.

Tan sólo precisa una breve consideración la aplicabilidad actual de esta norma a las dos esferas locales, relacionada con el hecho de que en el art. $20^{\circ}$ de aquél, en que ella se consagra, se hable de los recursos interpuestos al amparo de los Estatutos municipal y provincial.

Respecto al caso de los acuerdos provinciales, nada es preciso argüir puesto que el Estatuto está en vigor; y respecto a! de los municipales, la más elemental lógica indica que tal referencia, por ligarse con la reglamentación general de los recursos, nada obsta para la aplicación de lo dispuesto en el Decreto-Ley pese a' la sustitución del Estatuto municipal por la Ley de 31 de octubre de 1935, toda vez que ésta realiza, como quedó indicado, en su art. 225, declaración análoga a lạ del 256 de, aquél, en orden a la aplicabilidad para lo no previsto en ella (y concretamente en sus arts. 224 y 225), de la legislación vigente de lo contencioso administrativo.

Finalmente, en lo que toca a este punto, sólo nos resta señalar que el Tribuna! Supremo, en recientísima sentencia de $\mathbf{5}$ de enero de 1948, ha aplicado el Decreto-Ley de 14 de septiembre de 1925, diciendo, al recoger y admitir los considerandos del fallo apelado: :Que en cuanto a la excepción de incompetencia opuesta por la parte coadyuvante con fundamento en que ios recurrentes no pueden alegar derecho individual lesionado, tiene que ser desestimada con el sólo fundamento legal del Real Decreto-Ley anteriormente citado, según el cual sólo podrá proponerse por los fiscales y declararse por los tribunales la excepción de incompetencia de jurisdicción en los recursos contenciosos interpuestos contra acuerdos de autoridades y organismos municipales y provinciales al amparo de los $\cdot$ Estatutos municipal y provincial y de sus Reglamentos, cuando se trate de algunos de los casos comprendidos en el art. $2 .^{\circ}$ de 
dicho Real Decreto, siendo indudable que entre ellos no se encuentra el acuerdo recurridon.

Con ello se confirma el desarrollo que hemos realizado en orden a su vigencia, y se refuerza nuestra tesis sobre los particulares en este trabajo contenidos; interesando únicamente poner de manifiesto que si la sentencia últimamente citada se expresa a continuación de lo transcrito con cierto sentido dubitativo, ello es debido a que en la misma no se contiene ni realiza fundamentación alguna respecto a la pertinencia de la aplicación del precepto con arreglo al cual se falla, dadas las particularidades de su subsistencia actual, siendo quizá por la misma razón por lo que de ella parece deducirse una contemplación genérica y extensiva de dicho Decreto-Ley, cuando, como hemos visto, cada uno de los supuestos en él contenidos precisa, dadas aquellas particularidades, de una consideración específica y concreta (4).

\section{EnRIQUe Martínez Useros}

Dr. en Derecho. Profesor Adjunto de Derecho Administrativo en la Universidad de Sevilla

(4) V. de modo semejante la sentencia de 19 de diciembre de 1933 ; respecto al Real Decreto de 21 de octubre de 1924, relativo a la vigencia del Estatuto municipal en las provincias Vascongadas, con las modificaciones en dicho Decreto contenidas. 